\title{
Surgical correction of anomalous origin of right pulmonary artery from aorta in a four day old neonate
}

\author{
YVONNE D L SIBLEY, KEITH D ROBERTS, ERIC D SILOVE \\ From the Heart Unit, The Children's Hospital, Birmingham
}

SUMMARY A two day old neonate presented with cyanosis. The echocardiogram was misinterpreted as showing transposition of the great arteries. Cardiac catheterisation was performed the next day and showed anomalous origin of the right pulmonary artery from the aorta. Surgical correction at the age of $\mathbf{4}$ days was successful. At the age of nine months the patient was symptom free with "normal" cardiac anatomy. This patient is the youngest case to have successful correction of this anomaly. The initial misinterpretation of the echocardiogram could have had serious consequences if balloon atrial septostomy had been attempted.

Anomalous origin of the right pulmonary artery from the aorta is a rare congenital heart lesion; only about 60 cases have been reported. ${ }^{1-3}$ The value of cross sectional echocardiography in identifying communications between the ascending aorta and pulmonary trunk or individual pulmonary arteries has recently been described. ${ }^{4-6}$ We describe the youngest successfully treated patient and a difficulty that we had with echocardiographic diagnosis.

\section{Case report}

A two day old term male infant was referred with cyanosis and because of poor feeding. He was the second child of a 24 year old epileptic woman who had taken sodium valproate and carbamazepine throughout the pregnancy. He weighed $3.65 \mathrm{~kg}$ and was moderately cyanosed with mild tachypnoea and subcostal recession. There was a grade $2 / 4$ continuous cardiac murmur that was most intense at the left sternal edge. The liver edge was $3 \mathrm{~cm}$ below the costal margin. The chest radiograph showed cardiac enlargement and increased lung vascularity. The electrocardiogram showed right axis deviation and right ventricular hypertrophy.

On the echocardiogram in the long axis left parasternal view the posterior great vessel arising from

Requests for reprints to Dr Yvonne D L Sibley, The Children's Hospital, Ladywood Middleway, Birmingham B16 8ET. the left ventricle was considered to be the pulmonary artery while in the short axis view the vessel in the normal position of the pulmonary artery did not bifurcate (Fig. 1) and was interpreted as being the aorta. Transposition of the great arteries was therefore diagnosed. The arterial oxygen tension was $4.6 \mathrm{kPa}$. He was started on oral prostaglandin $E_{2}$ at a dose of $62.5 \mu \mathrm{g}$ hourly. Cardiac catheterisation was performed at the age of 3 days and showed that the right pulmonary artery arose from the aorta, which itself arose normally from the left ventricle. The left pulmonary artery continued from the main pulmonary artery which arose normally from the right ventricle. There was a ductus arteriosus. The right ventricular and main pulmonary arterial pressures were higher than the systemic pressure. Prostaglandin $\mathrm{E}_{2}$ was discontinued after cardiac catheterisation. Increasing heart failure developed despite fluid restriction, digoxin, and frusemide. Surgical correction was therefore undertaken at the age of four days.

The chest was opened via a median sternotomy, and the baby was cooled on bypass to an oesophageal temperature of $15^{\circ} \mathrm{C}$ and a nasopharygeal temperature of $15.6^{\circ} \mathrm{C}$. Under total circulatory arrest, the aorta was cross clamped distal to the origin of the right pulmonary artery. The ductus arteriosus was ligated. The right pulmonary artery was detached from the posterior wall of the ascending aorta and the aorta was repaired with interrupted sutures. A window was made in the right wall of the main pul- 


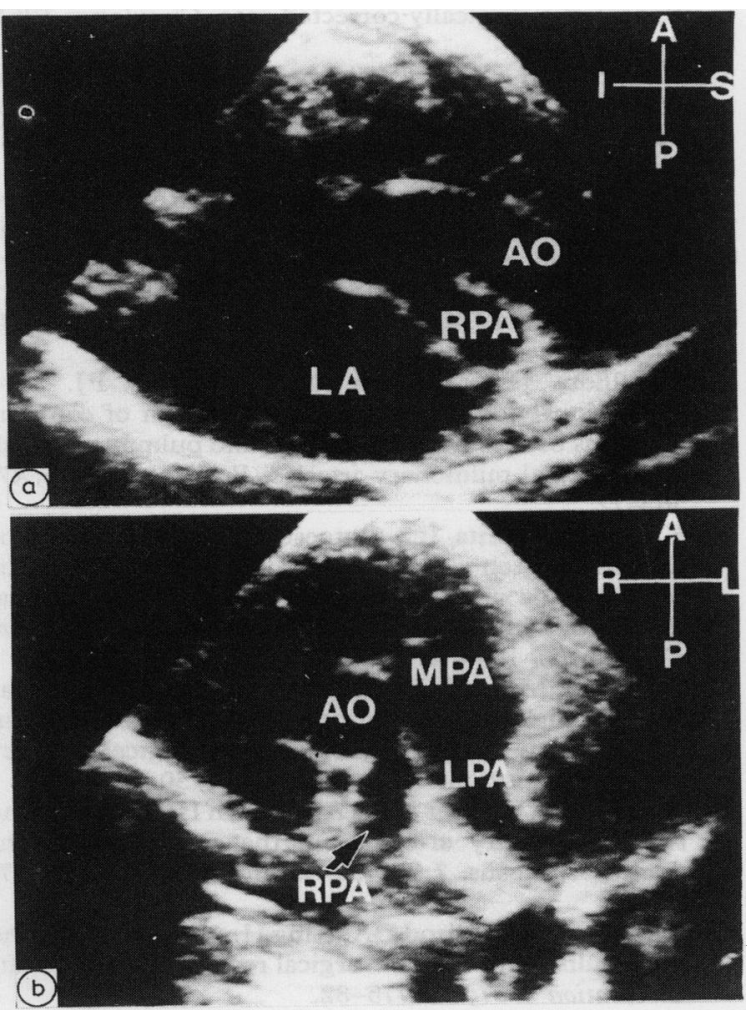

Fig. 1 Preoperative echocardiograms. (a) Long axis left parasternal view showing right pulmonary artery arising from aorta and giving appearance of a bifurcating great vessel. (b) Short axis left parasternal view showing aorta in cross section with right pulmonary artery arising from it. Main pulmonary artery continues as left pulmonary artery. $A O$, aorta; $M P A$, main pulmonary artery; $R P A$, right pulmonary artery; $L P A$, left pulmonary artery; $L A$, left atrium.

monary artery and the right pulmonary artery was anastomosed to it with interrupted sutures. Circulatory arrest lasted $\mathbf{4 0}$ minutes.

After operation he was found to have an absent left kidney and an obstructed right ureter, and nephroureteric surgery was performed. The echocardiogram showed the anastomosis of the right pulmonary artery to the main pulmonary artery (Fig. 2). He was discharged home at the age of seven weeks. Outpatient reviews when he was 11 weeks and 9 months old showed that he was thriving and had no important heart murmurs.

\section{Discussion}

Surgical correction of anomalous origin of the right

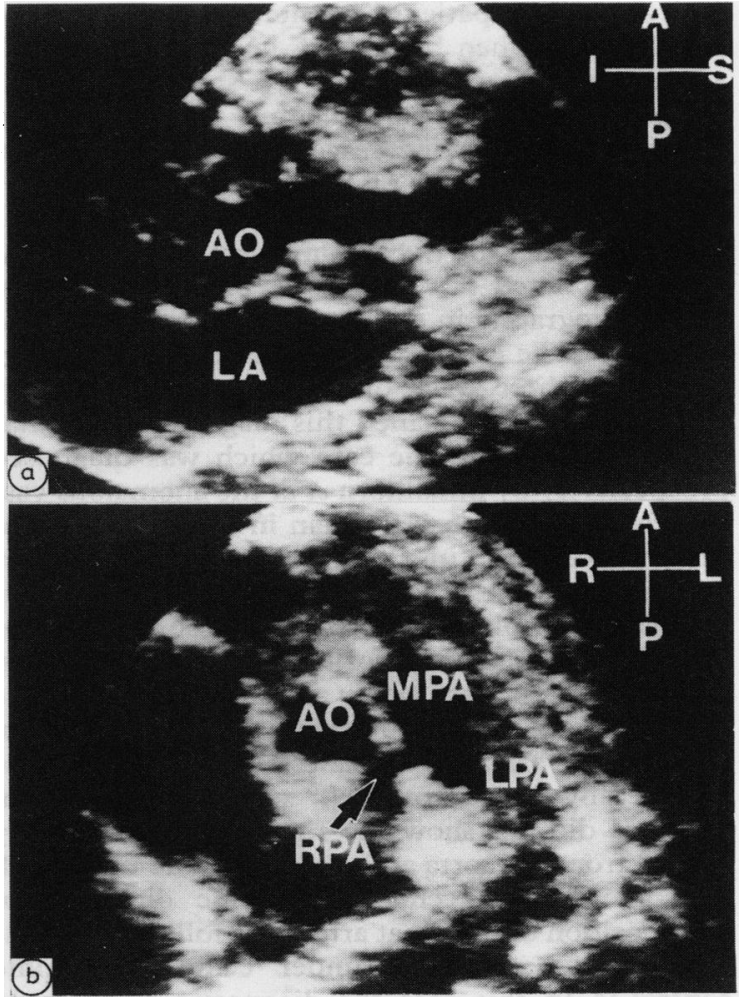

Fig. 2 Postoperative echocardiograms. (a) Long axis left parasternal view showing that aorta no longer has right pulmonary artery arising from it. (b) Short axis left parasternal view showing right pulmonary artery anastomosed to main pulmonary artery. Aorta is seen in cross section. $A O$, aorta; $M P A$, main pulmonary artery; $R P A$, right pulmonary artery; $L P A$, left pulmonary artery; $L A$, left atrium.

pulmonary artery from the aorta has been reported in several patients. ${ }^{7}$ This was achieved by a synthetic conduit to link the right and main pulmonary arteries, ${ }^{28}$ or by direct anastomosis ${ }^{6910}$ as in our patient. To date the youngest in whom correction was successful are the two three week old infants reported by King et $a l^{6}$ and Cumming et al. ${ }^{11}$ Our patient was four days old at operation. The fact that the right pulmonary artery originated from the posterior aspect of the ascending aorta enabled the surgeon to achieve a direct anastomosis of the right pulmonary artery to the main pulmonary artery without the use of a graft; this was an advantage in a baby who weighed only $3.65 \mathrm{~kg}$.

Most patients with this anomaly present with signs of congestive heart failure at the age of three to 
four weeks. Our patient presented with cyanosis and heart failure when he was 36 hours old. Cyanosis was probably due to right to left shunting through the patent foramen ovale. The use of prostaglandin $E_{2}$, which probably increased the left to right ductal flow, together with the renal abnormalities may have contributed to his early heart failure.

The origin of the right pulmonary artery from the aorta was noted retrospectively on cross sectional echocardiography in the neonate reported by Duncan et al. ${ }^{4}$ The prospective echocardiographic diagnosis in a three week old infant was reported by King et al who confirmed this diagnosis by cardiac catheterisation. ${ }^{6}$ In the case which was diagnosed prospectively by Smallhorn et al the anomalous vessel arose more superiorly than in our case and was readily recognised in a suprasternal cut. ${ }^{5}$ When we reviewed our initial echocardiogram for which we had used multiple views we saw that the appearances were not typical of transposition of the great arteries. The right pulmonary artery arose from the aorta at a less acute angle than is normally seen when a main pulmonary artery bifurcates. Unlike the case reported by Smallhorn et al, ${ }^{5}$ suprasternal views in our case did not show the right pulmonary artery arising from the aorta and were therefore unhelpful. In some centres echocardiographic diagnosis of transposition of the great arteries is followed by balloon atrial septostomy under echocardiographic control. ${ }^{12}$ In this case the diagnostic error could have had serious consequences and it is important to be aware of this pitfall.

\section{References}

1 Caro C, Lermanda VC, Lyons HA. Aortic origin of the right pulmonary artery. Br Heart $\mathcal{f}$ 1957; 19: 345-52.

2 Armer RM, Shumacker HB, Klatte EC. Origin of the right pulmonary artery from the ascending aorta.
Report of a surgically corrected case. Circulation 1961; 24: 662-8.

3 Kauffman SL, Yao AC, Webber CB, Lynfield J. Origin of the right pulmonary artery from the aorta. A clinicopathologic study of two types based on caliber of the pulmonary artery. Am $\mathcal{f}$ Cardiol 1967; 19: 741-8.

4 Duncan WJ, Freedom RM, Olley PM, Rowe RD. Two dimensional echocardiographic identification of hemitruncus: anomalous origin of one pulmonary artery from ascending aorta with the other pulmonary artery arising normally from right ventricle. Am Heart $\mathcal{F} 1981$; 102: 892-6.

5 Smallhorn JF, Anderson RH, Macartney FJ. Two dimensional echocardiographic assessment of communications between ascending aorta and pulmonary trunk or individual pulmonary arteries. $\mathrm{Br}$ Heart $\mathcal{F} 1982$; 47: 563-72.

6 King DH, Huhta JC, Gutgesell HP, Ott DA. Twodimensional echocardiographic diagnosis of anomalous origin of the right pulmonary artery from the aorta: differentiation from aortopulmonary window. $\mathcal{F} \mathrm{Am}$ Coll Cardiol 1984; 4: 351-5.

7 Keane JF, Maltz D, Bernhard WF, Corwin RD, Nadas AS. Anomalous origin of one pulmonary artery from the ascending aorta. Diagnostic, physiological and surgical considerations. Circulation 1974; 50: 588-94.

8 Kuypers PJ, Van der Maas AH, Busch HJ. Origin of the right pulmonary artery from the aorta with patent ductus arteriosus. 7 Thorac Cardiovasc Surg 1969; 57: 185-9.

9 Kirkpatrick SE, Girod DA, King H. Aortic origin of the right pulmonary artery. Surgical repair without a graft. Circulation 1967; 36: 775-82.

10 Matsuda H, Zavanella C, Lee P, Subramanian S. Aortic origin of the right pulmonary artery. Ann Thorac Surg 1977; 24: 374-8.

11 Cumming GR, Ferguson CC, Sanchez J. Aortic origin of the right pulmonary artery. Am $\mathcal{F}$ Cardiol 1972; 30: 674-9.

12 Allan LD, Leanage $R$, Wainwright $R$, Joseph $M C$ Tynan $M$. Balloon atrial septostomy under two dimensional echocardiographic control. Br Heart $\mathcal{F} 1982$; 47: 41-3. 